BioLink : Jurnal Biologi Lingkungan, Industri dan Kesehatan, Vol. 6 (1) Agustus (2019)

ISSN: 2356- 458X (print) ISSN: 2550-1305 (online)

BioLink

Jurnal Biologi Lingkungan, Industri, Kesehatan

Available online http://ojs.uma.ac.id/index.php/biolink

\title{
TINGKAT DAN POLA DISTRIBUSI INFESTASI PENGGEREK BATANG JAGUNG OSTRINIA FURNACALIS (LEPIDOPTERA: CRAMBIDAE) DI PADANGSIDIMPUAN
}

\section{INTENSITY AND DISTRIBUTION PATTERN OF CORN STEM BORER, OSTRINIA FURNACALIS (LEPIDOPTERA: CRAMBIDAE), IN PADANGSIDIMPUAN}

\author{
Muhammad Agung Permadi*, Qorry Hilmiyah Harahap \\ Prodi Agtoteknologi Fakultas Pertanian Universitas Muhammadiyah Tapanuli Selatan, \\ Indonesia
}

Diterima : 14-12-18; Disetujui : 26-04-19: Diterbitkan : 12-08-19

*Corresponding author: E-mail: muhammad.agungp@um-tapsel.ac.id

\begin{abstract}
Abstrak
Ostrinia furnacalis Guenee atau lebih dikenal sebagai penggerek batang jagung adalah hama utama tanaman jagung baik di Indonesia maupun di negara Asia lainnya. Penelitian ini bertujuan mengukur intensitas dan menganalisis pola sebaran infestasi 0 . furnacalis di pertanaman jagung. Pengamatan tanaman terinfestasi penggerek batang jagung dilakukan di 12 lahan jagung milik petani pada enam kecamatan di Kota Padangsidimpuan. Hasil penelitian menunjukkan lahan yang terinfestasi larva $O$. furnacalis terendah sebesar $1.1 \%$, sedangkan tertinggi sebesar $4.31 \%$. Infestasi larva $O$. furnacalis pada setiap tanaman di setiap lahan memiliki pola penyebaran acak dan berbeda-beda antara lahan pengamatan yang satu dengan lahan pengamatan yang lain.
\end{abstract}

Kata Kunci: Intensitas serangan, distribusi, Ostrinia furnacalis

\begin{abstract}
Ostrinia furnacalis Guenee as known as Asian corn stem borer is one of the main pests in corn cultivation practices in Indonesia. Besides Indonesia, these pests attack in other Asian regions such as Central Asia, East Asia, and also Australia. This study was aimed to measure the intensity of infestation and to analyze patterns of distribution of $O$. furnacalis in corn field. The observations of intensity and infestation distribusiton were held on 12 corn plantations owned by farmers in six sub-districts of Padangsidimpuan. Results showed that The lowest infested area of 0 . furnacalis larvae was $1.1 \%$, while the highest was $4.31 \%$. O. furnacalis larvae infestations at each plant in each plantations has a random distribution and the distribution was varies among corb fields.
\end{abstract}

Key Words: Intensity of infestasion, distribution , Ostrinia furnacalis

How to Cite: Permadi, M.A., dan Harahap, Q.H. (2019). Tingkat dan Pola Distribusi Infestasi Penggerek Batang Jagung Ostrinia furnacalis (Lepidoptera: Crambidae) di Padangsidimpuan, BioLink : Jurnal Biologi Lingkungan, Industri dan Kesehatan, Vol.6 (1): Hal. 25-31 
Permadi, M.A., dan Harahap, Q.H. Tingkat dan Pola Distribusi Infestasi Penggerek Batang Jagung Ostrinia furnacalis (Lepidoptera: Crambidae) di Padangsidimpuan

\section{PENDAHULUAN}

Jagung merupakan tanaman pangan sumber makanan pokok serta merupakan produk pertanian yang mempunyai peranan strategis dan ekonomis di Indonesia. Fungsi jagung selain sebagai bahan makanan dan pakan ternak, juga banyak dimanfaatkan sebagai sumber energi terbarukan serta bahan baku industri yang kebutuhannya selalu mengalami peningkatan. Pada tahun 2020, permintaan jagung di negara berkembang akan melebihi permintaan beras dan gandum. Permintaan jagung di seluruh dunia diprediksi akan melonjak 50\%, yaitu dari 558 juta ton (tahun 1995) menjadi 837 juta ton (tahun 2020) (Dirjen Tanaman Pangan 2011).

Salah satu faktor yang memengaruhi produktivitas jagung adalah adanya serangan organisme pengganggu tanaman (OPT). Nonci \& Masmawati menyatakan dalam penelitiannya hama Ostrinia furnacalis merupakan hama utama atau hama kunci pada tanaman jagung di Indonesia. Hama penggerek batang ini menyerang seluruh fase perkembangan tanaman dan seluruh bagian tanaman jagung. Hama ini menyerang berbagai wilayah di Indonesia, seperti di daerah, Sulawesi, Jawa, Sumatera, dan Nusa Tenggara (Dirjen Tanaman Pangan 2011). Sedangkan di luar negeri, hama ini juga menyerang wilayah Asia lainnya seperti

Australia, Asia Timur, dan juga Asia Tengah (Adnan 2011).

Besarnya kehilangan hasil ditentukan oleh kerapatan populasi larva 0. furnacalis serta umur tanaman pada saat terjadi serangan (Nonci 2004). Hama ini dapat merusak tongkol, bunga jantan dan menggerek batang yang menyebabkan tanaman menjadi patah dan nutrisi tidak dapat dibagikan keseluruh bagian tanaman. Sedangkan kerusakan yang terjadi pada daun menyebabkan terganggunya proses fotosintesis mengakibatkan turunnya produksi jagung (Surtikanti 2006).

Kehilangan produksi jagung akibat serangan 0 . furnacalis berkisar antara 2080\% (Bato et al. 1983). Penelitian yang dilakukan Abdullah dan Rauf (2011) di Kabupaten Bogor mendapatkan hasil bahwa dari 309 batang sampel tanaman jagung, lebih kurang 98\% terserang 0. furnacalis. Selanjutnya data survey jagung yang dilakukan Dirjen Tanaman Pangan (2011) pada bulan Maret sampai April 2013 di Sulawesi memperlihatkan intensitas serangan 0 . furnacalis berkisar 1,19-14,54\% dan di Jawa Tengah antara 1,61-8,89\%. Sedangkan penelitian Heryana (2013) menunjukkan, tingkat serangan hama 0 . furnacalis mencapai $52 \%$. 


\section{METODE PENELITIAN}

Pengamatan tanaman terinfestasi $O$. furnacalis dilaksanakan di 12 lahan tanaman jagung yang dimiliki petani pada enam kecamatan di Kota Padangsidimpuan. Masing-masing kecamatan tersebut adalah Kecamatan Padangsidimpuan Angkola Julu, Kecamatan Padangsidimpuan Batunadua, Kecamatan Padangsidimpuan Hutaimbaru, Kecamatan Padangsidimpuan Selatan, Kecamatan Padangsidimpuan Tenggara, Kecamatan Padangsidimpuan Utara.

Lahan pengamatan ditentukan berdasarkan kerapatan populasi tanaman jagung, yakni memiliki \pm 500 tanaman dengan jarak tanam $30 \mathrm{~cm} \times 70 \mathrm{~cm}$. Pengamatan tanaman terinfestasi furnacalis pada setiap lahan dilaksanakan sebanyak satu kali pada berbagai umur tanaman. Gejala serangan diamati pada masing-masing individu tanaman di setiap lahan. Pada setiap pengamatan, jumlah tanaman yang terinfestasi oleh $O$ furnacalis dicatat dan kemudian dihitung intensitas infestasinya. Intensitas Infestasi (II) O. furnacalis dihitung dengan rumus:

$$
\text { II }_{\text {of }}=\frac{\sum \text { jumlah batang terinfestasi }}{\sum \text { jumlah batang pengamatan }} x 100 \%
$$

\section{HASIL DAN PEMBAHASAN}

Hasil pengamatan di lapangan yang dilakukan pada berbagai umur tanaman mulai dari umur 30-75 hari menunjukan bahwa infestasi $O$. furnacalis sudah ditemukan pada umur tanaman 40 hari. Hal ini memperlihatkan bahwa keberadaan 0 . furnacalis di lahan pertanaman jagung sudah ada sebelum fase generatif dan terus ada seiring berkembangnya tanaman jagung. Adanya infestasi penggerek batang jagung . sebelum fase generatif, didukung oleh hasil penelitian Subiadi et al. (2014) yang menemukan bahwa penggerek batang jagung sudah mulai meletakkan telurnya pada umur tanaman 34 HST. Infestasi larva penggerek batang jagung pada beberapa lahan yang diamati dapat dilihat pada Tabel 1.

Tabel 1 Serangan larva O. furnacalis pada lahan jagung pada berbagai lokasi pengamatan di Kota Padangsidimpuan

\begin{tabular}{|c|c|c|c|c|c|}
\hline \multirow{2}{*}{ Lahan } & \multicolumn{2}{|c|}{ Lokasi } & \multirow{2}{*}{$\begin{array}{c}\text { Luas } \\
\text { lahan } \\
\left(\mathbf{m}^{2}\right)\end{array}$} & \multirow{2}{*}{$\begin{array}{c}\text { Umur } \\
\text { tanaman } \\
\text { (hari) }\end{array}$} & \multirow{2}{*}{$\begin{array}{c}\text { Jumlah } \\
\text { tanaman } \\
\text { terserang }\end{array}$} \\
\hline & Kecamatan & Kelurahan/Desa & & & \\
\hline L1 & PSP Selatan & Ujung Padang & 150 & 40 & 15 \\
\hline $\mathrm{L} 2$ & PSP Selatan & Aek Tampang & 600 & 75 & 60 \\
\hline L3 & PSP Angkola Julu & Pintu Langit & 200 & 30 & 0 \\
\hline $\mathrm{L} 4$ & PSP Angkola Julu & Rimba Soping & 150 & 40 & 0 \\
\hline L5 & PSP Batunadua & Pudun Jae & 660 & 50 & 33 \\
\hline L6 & PSP Batunadua & Siloting & 310 & 60 & 0 \\
\hline $\mathrm{L} 7$ & PSP Hutaimbaru & Sabungan & 150 & 75 & 0 \\
\hline L8 & PSP Hutaimbaru & Hutaimbaru & 250 & 75 & 0 \\
\hline L9 & PSP Tenggara & Palopat & 250 & 75 & 40 \\
\hline
\end{tabular}


Permadi, M.A., dan Harahap, Q.H. Tingkat dan Pola Distribusi Infestasi Penggerek Batang Jagung Ostrinia furnacalis (Lepidoptera: Crambidae) di Padangsidimpuan

\begin{tabular}{rccccr}
\hline L10 & PSP Tenggara & Salambue & 180 & 75 & 30 \\
L11 & PSP Utara & Losung Batu & 150 & 75 & 0 \\
L12 & PSP Utara & Panyanggar & 300 & 60 & 0 \\
\hline
\end{tabular}

Berdasarkan hasil pengamatan, ditemukan larva hama penggerek batang jagung (O. furnacalis) dengan ciri-ciri larva berwarna krem, kepala berwarna hitam, tubuh bagian atas berwarna kecoklatan, panjang tubuh larva antara 8-15 $\mathrm{mm}$ tergantung instar (Gambar 1). Hal ini sama dengan pendapat (Nurkomar 2013) yaitu larva dari 0 . furnacalis memiliki warna krem dengan warna coklat pada bagian atas tubuh.

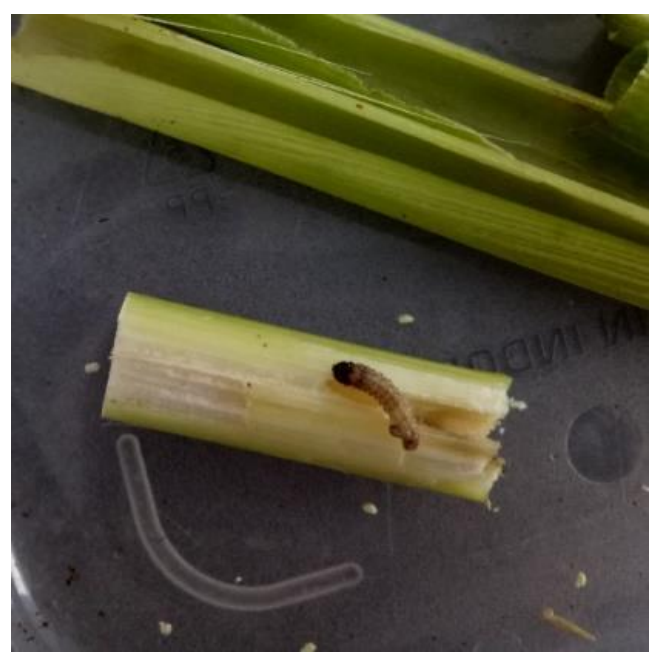

Gambar 1 Larva 0 . furnacalis instar III yang diambil dari batang jagung berumur 75 hari setelah tanam yang terinfestasi

Gejala kerusakan yang diakibatkan pada tanaman jagung sebagai berikut: larva menggerek ruas-ruas batang jagung mengakibatkan batang rebah karena gerekan tersebut. Bekas gerekan memiliki warna krem sampai kecoklatan yang keluar dari lubang gerekan (Gambar 2).
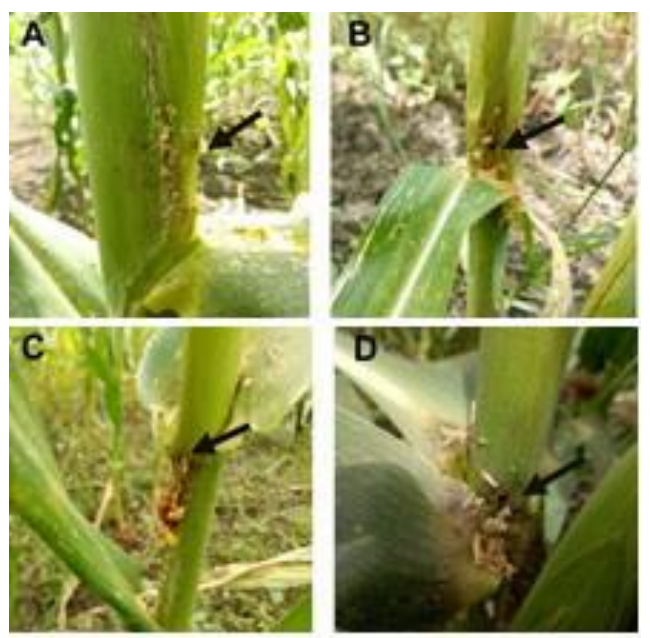

Gambar 2 Infestasi larva 0 . furnacalis pada batang jagung, (A, B) lubang gerekan larva $O$. furnacalis pada batang jagung, (C,D) bekas gerekan berwarna krem sampai coklat

Hasil pengataman juga menunjukkan tidak semua lahan jagung yang diamati diinfestasi oleh larva $O$. furnacalis. Lahan yang terinfestasi $O$. furnacalis terendah sebesar 1,1\% yaitu di Kelurahan Pudun Jae Kecamatan PSP Batunadua, sedangkan yang tertinggi sebesar 4,31\% pada lahan yang berada di Salambue Kecamatan PSP Tenggara. Pada lahan yang berada di Kelurahan/Desa Pintu Langit, Rimba Soping, Siloting, Hutaimbaru, Sabungan, Losung Batu dan Payanggar tidak ditemukan adanya infestasi $O$. furnacalis.

Hasil pengamatan menunjukkan jumlah tanaman terserang lebih tinggi pada tanaman jagung yang sudah berumur tua yaitu lebih dari 60 hari setelah tanam dan lebih rendah pada tanaman jagung 
berumur muda yaitu kurang dari 30 hari dan tidak mengaplikasikan praktek setelah tanam. Hal ini dimungkinkan budidaya rotasi tanaman. Infestasi yang karena fase generatif dari tanaman jagung tinggi juga dapat dikarenakan kurangnya merupakan fase yang disukai oleh $O$. sanitasi lingkungan ataupun tidak furnacalis untuk berkembang biak karena dilakukan pengendalian secara kimiawi. adanya ketersediaan makanan berupa Hal inilah yang kemudian menyebabkan bunga jantan dan betina. Hasil ini juga hama lebih leluasa menyerang tanaman mendukung hasil penelitan Da-Lopez et al. jagung untuk memperoleh makanan. Hasil (2014) yang menyatakan bahwa fase penelitian dari Patty (2012) menunjukkan generatif merupakan fase yang disukai bahwa adanya perlakuan yang diberikan oleh betina 0 . furnacalis untuk meletakkan terhadap tanaman jagung baik berupa telur, hal ini karena ketersediaan makanan pengendalian melalui sanitasi bunga berupa bunga jantan dan betina. jantan, pemberian pupuk dengan dosis

Selain itu lahan jagung yang yang tepat serta pengendalian kimiawi terinfestasi 0 . furnacalis disebabkan pola dapat menurunkan intensitas infestasi penanaman jagung yang terus menerus larva O. furnacalis.

Tabel 2 Intensitas infestasi larva 0 . furnacalis pada lahan jagung pada berbagai lokasi pengamatan di Kota Padangsidimpuan

\begin{tabular}{cccrc}
\hline \multirow{2}{*}{ Lahan } & \multicolumn{2}{c}{ Lokasi } & $\begin{array}{c}\text { Intensitas } \\
\text { infestasi (\%) }\end{array}$ & $\begin{array}{c}\text { Pola } \\
\text { penyebaran }\end{array}$ \\
\cline { 2 - 4 } & Kecamatan & Kelurahan/Desa & & acak \\
\hline L1 & PSP Selatan & Ujung Padang & 3,15 & acak \\
L2 & PSP Selatan & Aek Tampang & 3,08 & - \\
L3 & PSP Angkola Julu & Pintu Langit & 0 & - \\
L4 & PSP Angkola Julu & Rimba Soping & 0 & acak \\
L5 & PSP Batunadua & Pudun Jae & 1,10 & - \\
L6 & PSP Batunadua & Siloting & 0 & - \\
L7 & PSP Hutaimbaru & Sabungan & 0 & - \\
L8 & PSP Hutaimbaru & Hutaimbaru & 0 & acak \\
L9 & PSP Tenggara & Palopat & 3,33 & - \\
L10 & PSP Tenggara & Salambue & 4,31 & - \\
L11 & PSP Utara & Losung Batu & 0 & 0 \\
L12 & PSP Utara & Panyanggar & 0 & \\
\hline
\end{tabular}

Keterangan: (-) tidak terinfestasi

Infestasi larva 0 . furnacalis pada penyebaran infestasi larva O. furnacalis setiap tanaman di setiap lahan memiliki dapat dideskripsikan seperti pada Gambar pola penyebaran yang menyebar secara 3. Tidak semua tanaman dalam satu lahan acak dan berbeda-beda antara lahan terinfestasi larva O. furnacalis. Demikian pengamatan yang satu dengan lahan juga dalam satu baris tidak semua pengamatan yang lain. Secara umum pola terinfestasi larva 0 . furnacalis bahkan ada 
yang sama sekali tidak dijumpai adanya lapangan sedikit. Hal ini didukung oleh larva O. furnacalis (Gambar 3A, 3B,3C). penelitian Southwood dan Henderson Hasil pengamatan ini sesuai dengan (2000) bahwa saat populasi rendah penelitian Amaliah (2017) dan Nurkomar sebaran hama cenderung acak yang (2013) yang menunjukkan bahwa pola memungkinkan setiap individu untuk distribusi investasi $\quad$ o. furnacalis menempati setiap unit contoh. cenderung acak jika populasinya di
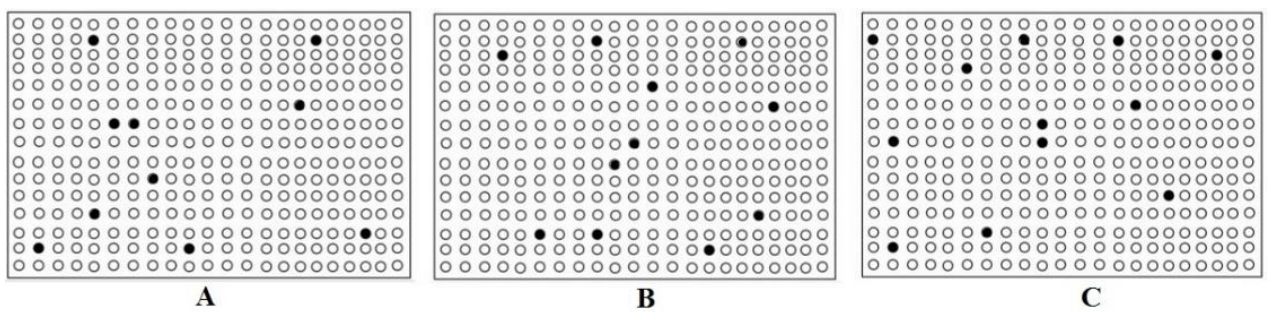

Gambar 3 Pola penyebaran infestasi larva O. furnacalis di lahan. Pola penyebaran di lahan jagung Kelurahan Ujung Padang dan Pudun Jae (A); lahan jagung di Kelurahan Palopat dan Salambue (B); dan lahan jagung di Kelurahan Aek Tampang (C). Keterangan : $(\bullet)$ tanaman terinfestasi telur O. furnacalis, (O)

\section{SIMPULAN}

Lahan yang terinfestasi larva $O$. furnacalis terendah sebesar 1,1\% yaitu di Kelurahan Pudun Jae Kecamatan PSP Batunadua, sedangkan yang tertinggi sebesar 4,31\% pada lahan yang berada di Salambue Kecamatan PSP Tenggara. Pada lahan yang berada di Kelurahan/Desa Pintu Langit, Rimba Soping, Siloting, Hutaimbaru, Sabungan, Losung Batu dan Payanggar tidak ditemukan adanya infestasi $O$. furnacalis. Infestasi larva $O$. furnacalis pada setiap tanaman di setiap lahan memiliki pola penyebaran yang menyebar secara acak dan berbeda-beda antara lahan pengamatan yang satu dengan lahan pengamatan yang lain.

\section{UCAPAN TERIMAKASIH}

Penulis mengucapkan terima kasih kepada APB Universitas Muhammadiyah Tapanuli Selatan yang telah membantu pendanaan sehingga penelitian ini dapat terlaksana.

\section{DAFTAR PUSTAKA}

[Dirjen Tanaman Pangan] Direktorat Jenderal Tanaman Pangan. (2011). Teknologi Budidaya Jagung. Jakarta (ID): Direktorat Jenderal Tanaman Pangan.

Abdullah T, Rauf A. (2011). Karakteristik populasi dan serangan penggerek batang jagung Asia, Ostrinia furnacalis (Lepidoptera: Pyralidae), dan hubungannya dengan kehilangan hasil. Fitomedika. 7(3): 175-181.

Adnan AM. (2011). Manajemen utama musuh alami hama utama jagung. Di dalam: Prosiding Seminar Nasional Serealia; 2011 Jun 15; Maros. Maros (ID): Balai Penelitian Tanaman Serealia.

Amaliah AD. (2017). Tingkat dan pola distribusi infestasi dua hama utama jagung di Kecamatan Dramaga Bogor [skripsi]. Bogor (ID): Institut Pertanian Bogor.

Bato SM, Everett TR, Malijan OO. (1983). Integrated Pest Management for Asian Corn 
Borer Control. Phillippine (PH): National Crop Protection Centre Series.

Da-Lopez YF, Trisyono YA, Witjaksono, Subiadi. (2014). Pola sebaran kelompok telur Ostrinia furnacalis Guenee (Lepidoptera: Crambidae) pada lahan jagung. J Entomol Indones. 12(2): 81-92.

Heryana RTS. (2013). Penggerek batang jagung Ostrinia furnacalis Guenée (Lepidoptera: Crambidae): tingkat serangan di wilayah Bogor dan siklus hidupnya di laboratorium [skripsi]. Bogor (ID): Institut Pertanian Bogor.

Nonci N, Masmawati. (2005). Kemampuan jelajah Trichogramma evanescens Westwood, parasitoid telur penggerek batang jagung (Ostrinia furnacalis). Di dalam: Prosiding Seminar Nasional Jagung; 2005 Sep 29-30; Maros. Maros (ID): Balai Penelitian Tanaman Serealia.

Nonci N. (2004). Biologi dan musuh alami penggerek batang Ostrinia furnacalis Guenée (Lepidoptera: Pyralidae) pada tanaman jagung. Jurnal Litbang Pertanian. 23(1):9-10.

Nurkomar I. (2013). Populasi dan musuh alami telur penggerek batang jagung asia Ostrinia furnacalis Guenée (Lepidoptera: Crambidae) di wilayah Bogor [skripsi]. Bogor (ID): Institut Pertanian Bogor.

Patty JA. (2012). Teknik pengendalian hama Ostrinia furnacalis pada tanaman jagung manis. J Agroforest. 7(1): 50-58.

Southwood TRE, Henderson PA.(200o). Ecological methods. $3^{\text {rd }}$ ed. UK: Blackwell Science.

Subiadi, Trisyono YA, Martono E. (2014). Pola sebaran kelompok telur Ostrinia furnacalis Gueneè (Lepidoptera: Crambidae) pada beberapa fase pertumbuhan tanaman jagung (Zea mays L.). J Perlin Tan Indones. 18(1): 33-40.

Surtikanti. (2006). Potensi parasitoid telur sebagai pengendali hama penggerek batang dan penggerek tongkol jagung. Jurnal Iptek Tanaman Pangan. 2: 192-194. 